\title{
Analysis on Micro Complex Shape Via Hole Punching on Low Temperature Co-Fired Ceramics
}

\author{
Vahdat Astani Chee, Junfeng Yang, Zuyuan Yu* \\ Key Laboratory for Precision and Non-Traditional Machining Technology of Ministry of Education, \\ Dalian University of Technology, Dalian, China \\ Email: *zyu@dlut.edu.cn
}

How to cite this paper: Chee, V.A., Yang, J.F. and Yu, Z.Y. (2020) Analysis on Micro Complex Shape Via Hole Punching on Low Temperature Co-Fired Ceramics. New Journal of Glass and Ceramics, 10, 1-13. https://doi.org/10.4236/njgc.2020.101001

Received: December 22, 2019

Accepted: January 28, 2020

Published: January 31, 2020

Copyright (๑) 2020 by author(s) and Scientific Research Publishing Inc. This work is licensed under the Creative Commons Attribution International License (CC BY 4.0).

http://creativecommons.org/licenses/by/4.0/ (c) (i) Open Access

\begin{abstract}
The quality of a via hole on a multilayer stack of Low Temperature Co-fired Ceramic (LTCC) tape is of utmost importance to its functionality. This paper investigates a substitute for the commonly used circular shape hole to a more complex one and its implications when different parameters such as sheet thickness, punch speed, travel distance and tool clearance are changed. Fabrication of the punch tools and the punching process is carried out at the same machine, ensuring alignment. Two types of non-circular shape are chosen to carry out the experiment. Pre-sintered complex shape hole measurements show that while punch conditions such as speed and tool gap have little effect on the size, sheet thickness and travel depth play a vital role in the overall dimension. Albeit having only a slight effect on the size, those parameters are significant in other aspects of hole quality. Post-sintering investigation is also observed and discussed.
\end{abstract}

\section{Keywords}

Low Temperature Co-Fired Ceramic Packaging, Non-Circular Via Holes, Micro-Hole Punching

\section{Introduction}

Once being seen as a promising breakthrough in electronics decades ago, multilayer Low Temperature Co-Fired Ceramics (LTCC) technology went through a downfall after the passing of the millennia due to the process complexity and limited production usage. The upcoming era of industry 4.0 however, is giving a strong push towards a more specified and customized application based electronics. Co-fired ceramics still holds a promising future in electronics. Ceramics 
is widely used in microelectronics as a monolithic device where the entire support structure, including the conductive, resistive and dielectric materials is sintered at the same instance, creating an independently functioning micro system [1]. The technology is also used in electronic packaging for its high resistance to environmental stress [2].

Casted ceramic sheets are commonly printed with conductive ink on its surface to create electrical paths. The sheets are then stacked in its green state (pre-sintering) where via holes are aligned between the sheets and then filled with conducting material, thus creating an interconnection between the sheets [3]. Quality and alignment of these circular via holes are of utmost importance to achieve a fully functioning system [4]. All via holes are commonly circular due to the ease of the punching alignment and uniformity of the via filling process. Deformed via holes are often regarded as the main cause of functional failure in an integrated device. These via holes are mainly mechanically punched in various sizes depending on the sheet and product. With the advancement of consumer electronics and the ever advancing miniaturization of products, it is only natural there is a need that the size requirements of these micro holes are reduced. The punching process of these holes includes a pneumatic or electric driven punch head that moves in multiple axes and a fixed die. A typical sheet could have as many as 2000 punched holes, all to be aligned with holes or marks on the corresponding sheet. Post-sintering shrinkage is also an important factor in the design and evaluation of the holes [5]. The evaporation of solvents and the combustion of the polymer binder from its green state during sintering process shrink the tape significantly, some deformation naturally occurs [6].

Due to the significant number of connecting holes on a single sheet by reason of its shape, this study analyzes the quality of a complex shaped hole as a substitute for a circular shape. The complex shape which comprises of a combination of circles and rectangles, could pave way to a simpler design of electrical path and less punched hole on a sheet. This study will analyze the quality of a single LTCC sheet without its polymer protection within different parameters such as punch speed, punch depth, sheet thickness, etc. Previous studies conducted on the quality of micro circular holes on LTCC sheets have shown that debris and slugs are a present challenge for mechanically punched vias [7]. Therefore this study also conducts experiments on different punch-die gaps on non-circular holes. The punch process includes a mechanical punch and die fabricated by a self developed machine.

\section{Experimental Methodology}

\subsection{Experimental Setup}

Ceramic sheet mainly composed of Aluminum Oxide and some other composite glass ceramics was prepared in its green state with different casted thickness. They were cut into pieces of $15 \mathrm{~mm} \times 65 \mathrm{~mm}$. A multiple axis micro machining equipment is used to create the punch tool and die, embedded along with it a 
punching stage to carry out the punching process. This equipment, shown in Figure 1 is designed to have a travel repeatability of up to $1 \mu \mathrm{m}$ on each axis. The two main chambers of the machine, namely the tool fabrication chamber and the punch chamber, lies on the same axis, easing alignment.

The experiment consists of a punch test, in which different parameters of the sheet and punch process are tested, and a gap test, in which various clearance of the tools are tested. In both cases, sheets are punched in their green state and sintered later on.

\subsection{Variable Punch Parameters Experiment Design}

The complex shape chosen for the experiment is two domes on the end of a rectangle as seen with dimensional values in Figure 2 [8]. Mechanically punched LTCC holes naturally follow die size rather than the punch. Due to the complexity of this particular form, the theoretical gap between the punch tool and die is designed at $10 \mu \mathrm{m}$.

The equipment uses Wire Electrical Discharge Machining (WEDG), a method of Electrical Discharge Machining (EDM) technology, to fabricate a micro tool head which in turn machines the die [9]. This tool head will be termed as an Electrode. Due to the complexity of the shape, two dies of the same shape are machined. One for the actual punch process, and the other to create the punch tool by reverse-EDM, a technique where the polarity of the machining is inverted and the die machines the punch tool [10]. In this case, the punch tool and die is made of tungsten carbide. Figure 3 further clear these steps. The male and female sides are machined to a height of $0.2 \mathrm{~mm}$ and $0.3 \mathrm{~mm}$ respectively.

On top of the different sheet thickness, it should also be proven that punch speed and depth would have various effects on the result of a complex shape via hole. Three different sheet thickness of 250,300 and $600 \mu \mathrm{m}$ is tested against 1 , 10 and $20 \mathrm{~mm} / \mathrm{s}$ travel speed and distance of $100 \%, 110 \% \& 120 \%$ of thickness as seen in Table 1. Punch travel is counted from the top layer of the sheet.

\subsection{Variable Gap Experiment Design and Parameters}

S. H. Rhim et al. stated that massive burr occurs as tool tolerance increased in double layer green sheet with PET Mylar on circular via holes [11]. In order to prove that this statement still applies on non-circular via holes, further experiments are conducted on different gap sizes. For this test, the shape is chosen to be a $100 \mu \mathrm{m} \times 120 \mu \mathrm{m}$ rectangle. To achieve this, micro electrode made of tungsten carbide is directly machined into the required punch tool shape with the tip having a smaller size than the body with WEDG. The tip is then used to construct the die. The die used in the experiment is a copper sheet of $0.3 \mathrm{~mm}$ thickness. EDM machining process naturally creates a gap between the two parts, which is ideally $10 \mu \mathrm{m}$. The tip is then cut-off and the rectangular electrode is used to punch the workpiece [12]. Various electrodes prepared with different tip dimensions enable the creation of different tool clearance, the smaller the tip size the smaller the gap. The experiment uses three different tip offsets, 
the first same size as the body, 5 and $10 \mu \mathrm{m}$ smaller as seen in Figure 4. All punch tests are done on the same travel speed of $20 \mathrm{~mm} / \mathrm{s}$.

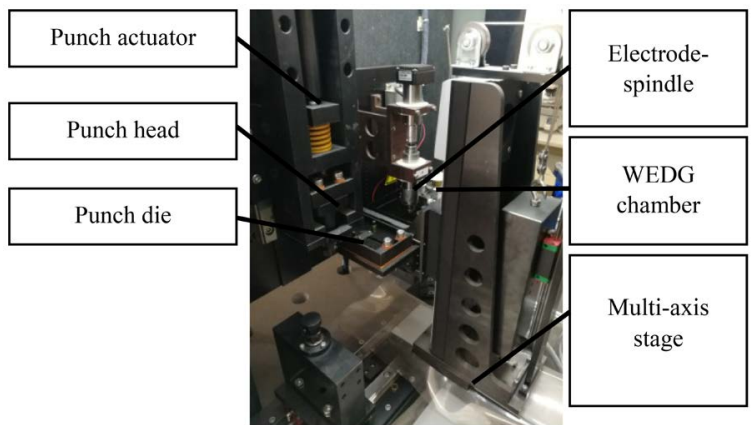

Figure 1. Multi axis micro machine.

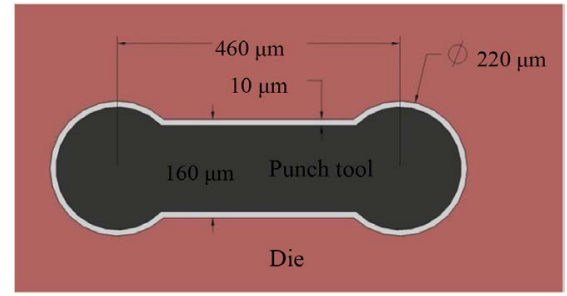

Figure 2. Form and dimension of complex shape punch tool and die.

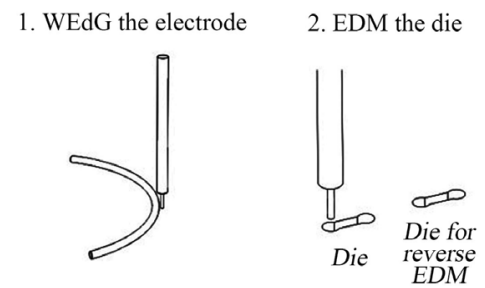

3. Reverse EDM the punch 4. Punch workpie
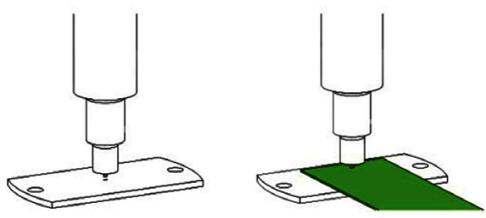

Figure 3. Tool fabrication and punching process of complex shape via hole.

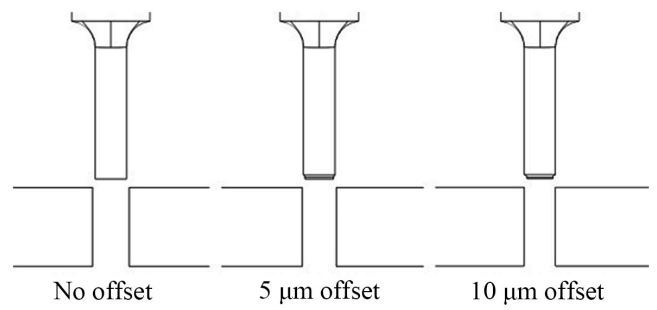

Figure 4. Different stepped tungsten carbide electrode tip offset used to fabricate different punching gaps. 
Table 1. Punching parameters of complex shape via hole (in $\mu \mathrm{m}$ ).

\begin{tabular}{ccccc}
\hline \multirow{2}{*}{ Speed } & $\begin{array}{c}\text { \% of } \\
\text { thickness }\end{array}$ & $250 \mu \mathrm{m}$ & $300 \mu \mathrm{m}$ & $600 \mu \mathrm{m}$ \\
\cline { 3 - 5 } & $100 \%$ & 250 & 300 & 600 \\
\hline \multirow{2}{*}{$1 \mathrm{~mm} / \mathrm{s}$} & $110 \%$ & 275 & 330 & 660 \\
& $120 \%$ & 300 & 360 & 720 \\
& $100 \%$ & 250 & 300 & 600 \\
$10 \mathrm{~mm} / \mathrm{s}$ & $110 \%$ & 275 & 330 & 660 \\
& $120 \%$ & 300 & 360 & 720 \\
& $100 \%$ & 250 & 300 & 600 \\
& $110 \%$ & 275 & 330 & 660 \\
& $120 \%$ & 300 & 360 & 720 \\
\hline
\end{tabular}

\subsection{Measurement}

All test results are observed with an Olympus STM6 measuring microscope pre and post sintering. Formation of warpage is analyzed through a Scanning Electron Microscope (SEM). To improve scanning results, the workpieces are coated through vapor deposition of gold $(\mathrm{Au})$. The resolution imitated of the coating is $0.1 \mu \mathrm{m}$ hence negligible. The co-firing process starts with burning out of the solvents at $300^{\circ} \mathrm{C}$ for 50 minutes and then sintering at $900^{\circ} \mathrm{C}$ [13]. The complete spectrum can be seen on Graph 1 .

\section{Results and Discussion}

Results of the experiments conducted was used as base to observe and investigate tool fabrication and punched hole quality. Figure 5, a microscope image of the double circle complex shape, calculates to a gap of $9.022 \mu \mathrm{m}$ in the vertical direction, an offset of about $1 \mu \mathrm{m}$ from its designed value. Measurement is also taken on the centre distance of two circles and in this case shows an adequate precision for the test. Certain level of roughness is detected on the corners of the punch tool due to the nature of the reverse-EDM but can be omitted due to its minute extent.

Electrode was successfully shaped into a rectangle with each corner at $90^{\circ} \pm$ $1^{\circ}$. Figure 6 shows the electrode after the first and second sides cut off. Locating the center of the electrode was of utmost importance as to get an exact sizing of the shape, as the machine spindle core does not necessary correlate to the electrode center point. Some challenges were met during the tool making of the gap test, namely to fabricate a micro tip of $10 \mu \mathrm{m}$ and $5 \mu \mathrm{m}$ with the machine's accuracy of $1 \mu \mathrm{m}$ and the feeding rate of EDM. Spark gap between the electrode and workpiece in EDM is an unavoidable phenomenon that results in an inevitable error.

That being said, the tips were produced and Figure 7 shows the difference of 
the straight tip and the smaller tip of $10 \mu \mathrm{m}$, where the height $(\mathrm{H})$ of the straight electrode rectangle was measured at $118.927 \mu \mathrm{m}$. Whereas the total difference of the inner tip and main body of the stepped electrode stands at $18.599 \mu \mathrm{m}$ (L2 L1), each side with a dimension and accuracy of $10 \mu \mathrm{m} \pm 2 \mu \mathrm{m}$.

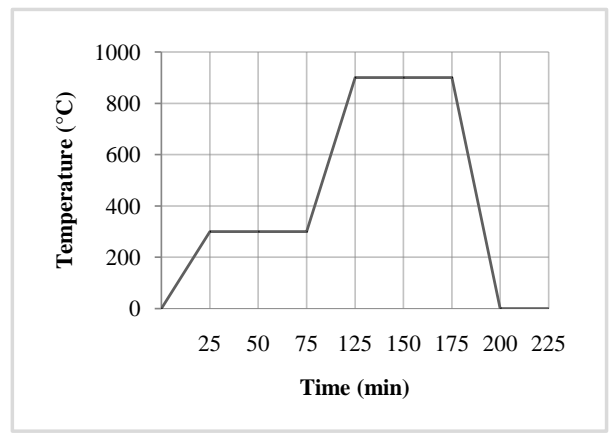

Graph 1. Experiment sintering temperature and duration.

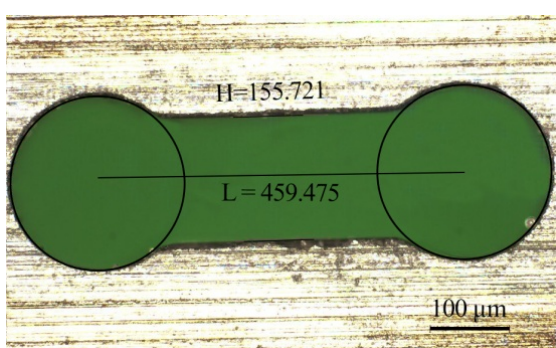

(a)

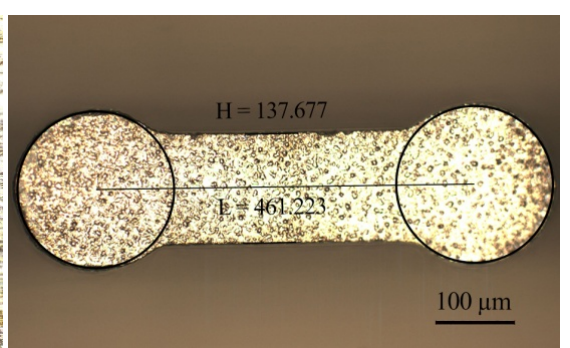

(b)

Figure 5. Fabricated (a) punch die and (b) punch head measurements.

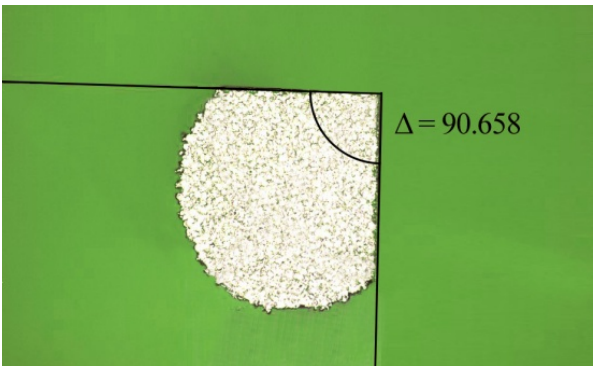

Figure 6. Corner angle value of rectangular electrode.

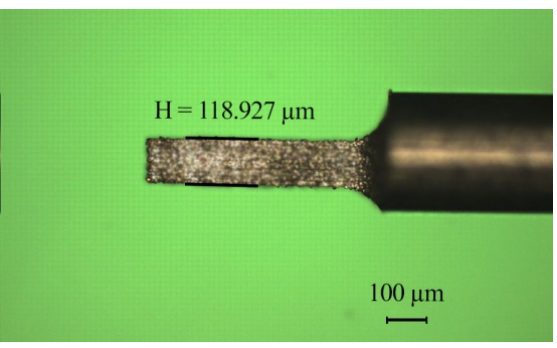

(a)

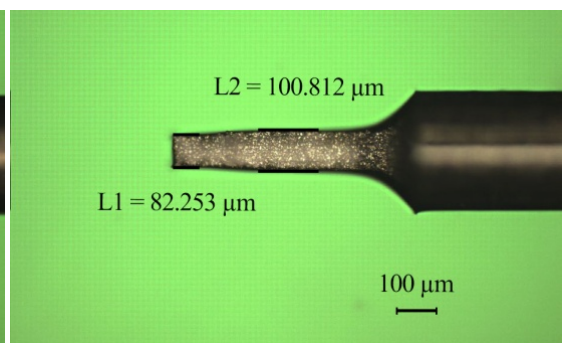

(b)

Figure 7. Tungsten carbide electrode with different tip offsets: (a) side view of straight no offset tip and (b) side view of $10 \mu \mathrm{m}$ offset tip. 
Table 2 shows the dimensions of the rectangular punch tool and die height and length with the average of 5 measurement takings. It can be deduced that the tools were successfully machined to its acceptable dimensional requirements. Punch tool with $10 \mu \mathrm{m}$ offset resulted in a die size about $3 \mu \mathrm{m}$ larger than the electrode punch head.

Images on Figure 8 and Figure 9 show the quality of the electrode punch and copper die. Some circular indentation can be seen on the female die that is not seen on the male punch tip. This is assumed to be due to the uneveness of the EDM rate. Workpiece punch results will take into account whether or not these shapes are translated into the ceramic sheets.

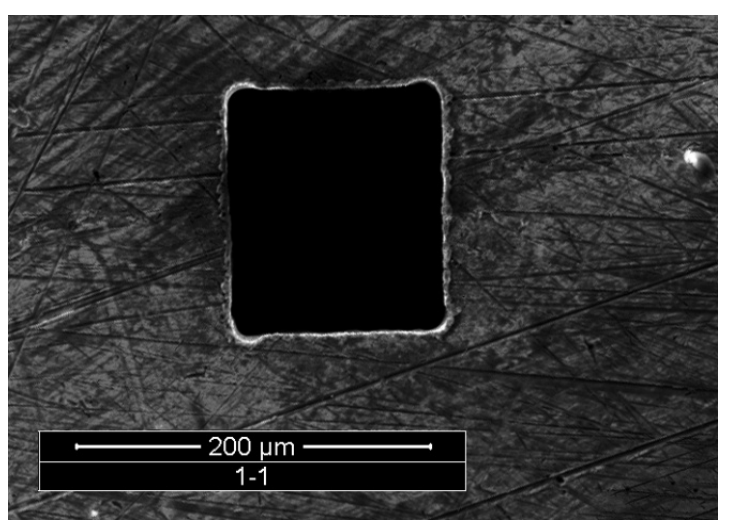

Figure 8. SEM image of copper rectangular die mold with no offset.

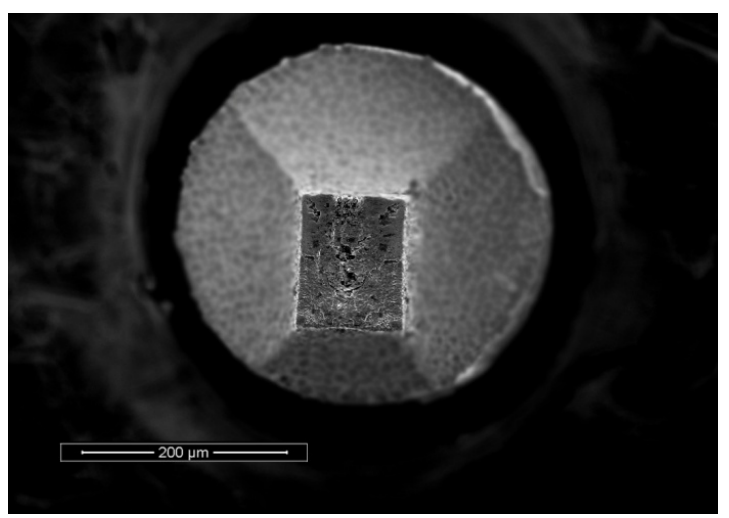

Figure 9. SEM image of electrode punch mold no offset tip.

Table 2. Average measured dimensions of rectangular punch tool and die height and length.

\begin{tabular}{ccccccc}
\hline & \multicolumn{2}{c}{ No offset } & \multicolumn{2}{c}{$5 \boldsymbol{\mu m}$ offset } & \multicolumn{2}{c}{$10 \mu \mathrm{m}$ offset } \\
\cline { 2 - 7 } & H & L & H & L & H & L \\
\hline Punch tip & 118.927 & 101.285 & 109.783 & 92.409 & 101.229 & 82.253 \\
Die & 139.524 & 122.628 & 131.091 & 112.198 & 123.623 & 103.884 \\
\hline
\end{tabular}




\subsection{Variable Punch Parameters Experiment Results}

Samples gathered were measured in the concentric center distances of the two circles $(\mathrm{L})$ and the height of the rectangle $(\mathrm{H})$ taken from its top view. An average of 3 measurement of each sample was calculated. Table 3 shows the full outcome group in terms of different speed on the main row and different sheet thickness on the main columns. Taken the target size of $\mathrm{L}$ to be $460 \mu \mathrm{m}$, Graph 2 explicitly shows that the $600 \mu \mathrm{m}$ sheet thickness has a significant offset the required line. It averages an offset of $8.356 \mu \mathrm{m}$ from ideal. It is also true that compared to the other two thickness, it is has the poorest result. It is also evident that deeper punch distance has an effect towards the result as the graph shows a downward trend on almost every line. The same manifests in the $\mathrm{H}$ dimension, where different depths brings the size closer to the desired size. On the contrary, travel speed did not have too large of an effect. Although there are some improvements at the accelerated punch speed, but they are overall minimal. This is assumed due to the nature of pre-sintered LTCC tapes that are flexible hence the shearing force initiates fracture at a much lower requirement.

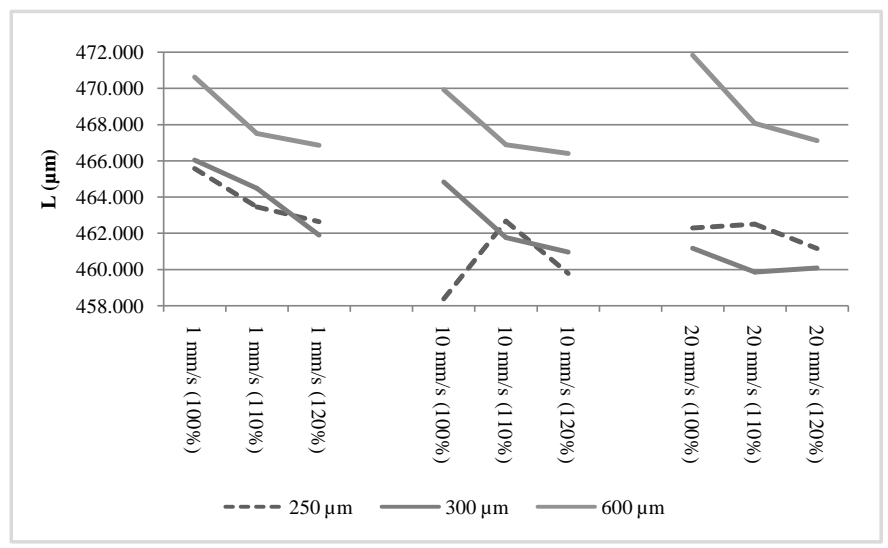

Graph 2. Comparison of pre-sintered via circle distance in terms of punch speed and sheet thickness.

Table 3. Pre-sintered complex shape via hole punched result measurement (in $\mu \mathrm{m}$ ).

\begin{tabular}{|c|c|c|c|c|c|c|c|}
\hline \multirow{3}{*}{ Speed } & \multirow{3}{*}{ Depth } & \multicolumn{6}{|c|}{ Sheet Thickness } \\
\hline & & \multicolumn{2}{|c|}{$250 \mu \mathrm{m}$} & \multicolumn{2}{|c|}{$300 \mu \mathrm{m}$} & \multicolumn{2}{|c|}{$600 \mu \mathrm{m}$} \\
\hline & & $\mathrm{L}$ & $\mathrm{H}$ & $\mathrm{L}$ & $\mathrm{H}$ & $\mathrm{L}$ & $\mathrm{H}$ \\
\hline \multirow{3}{*}{$\begin{array}{c}1 \\
\mathrm{~mm} / \mathrm{s}\end{array}$} & $100 \%$ & 465.575 & 146.880 & 466.042 & 144.760 & 470.619 & 147.062 \\
\hline & $110 \%$ & 463.449 & 143.004 & 464.489 & 144.229 & 467.510 & 145.721 \\
\hline & $120 \%$ & 462.633 & 139.474 & 461.896 & 141.487 & 466.855 & 145.181 \\
\hline \multirow{3}{*}{$\begin{array}{c}10 \\
\mathrm{~mm} / \mathrm{s}\end{array}$} & $100 \%$ & 458.379 & 144.752 & 464.830 & 142.589 & 469.931 & 146.255 \\
\hline & $110 \%$ & 462.669 & 144.110 & 461.763 & 141.433 & 466.889 & 147.297 \\
\hline & $120 \%$ & 459.773 & 141.206 & 460.956 & 140.399 & 466.397 & 147.706 \\
\hline \multirow{3}{*}{$\begin{array}{c}20 \\
\mathrm{~mm} / \mathrm{s}\end{array}$} & $100 \%$ & 462.294 & 144.554 & 461.175 & 139.422 & 471.833 & 144.277 \\
\hline & $110 \%$ & 462.498 & 141.084 & 459.859 & 141.849 & 468.059 & 143.093 \\
\hline & $120 \%$ & 461.150 & 139.834 & 460.086 & 140.745 & 467.112 & 143.109 \\
\hline
\end{tabular}


Representation shown on Figure 10 is taken from $110 \%$ at $10 \mathrm{~mm} / \mathrm{s}$ for different sheet thickness. It is rather noticeable that there are darkened shades on the edges of the $600 \mu \mathrm{m}$ sheet, which means the hole is on an angled slope. Similar instances are found throughout samples from this thickness, making it questionable for further usage. The limited to none existing shades at the $250 \mu \mathrm{m}$ and $300 \mu \mathrm{m}$ samples indicates that the samples are rather straight and satisfactory for further handling. Both these thicknesses show promising results in terms of average calculated size and hole features.

Results seen from SEM images also confirms that the complex shape of the two lesser thicknesses comply with quality required for via filling, i.e. minimal burrs on the sides and no displacement of ceramic particles. The picture shown in Figure 11(a) explains from a top view, a clean cut is produced and there are minimal rough corners around the rectangular path. Figure 11(b) shows the innate character of a punched green state sheet where the inner walls exhibit pre-bonded ceramics. The thicker thickness of $600 \mu \mathrm{m}$ had poorer quality across the corners and a less smooth cut. Some particles measured were up to $70 \mu \mathrm{m}$ in size and may have an adverse effect on the electrical properties after via filling. These phenomena can be seen across samples of this particular thickness with the example given in Figure 12. It also demonstrates that particle build up starts not just from the corners at the top but also from along the inner body walls, most likely due to uneven mixing of slurry during sheet casting on PET sheet. Standard procedures of via filling allow some degree of surface and corner irregularity because they are likely to disappear or flatten during the sintering process. That being said, the magnitude of these proportions is typically not accepted.

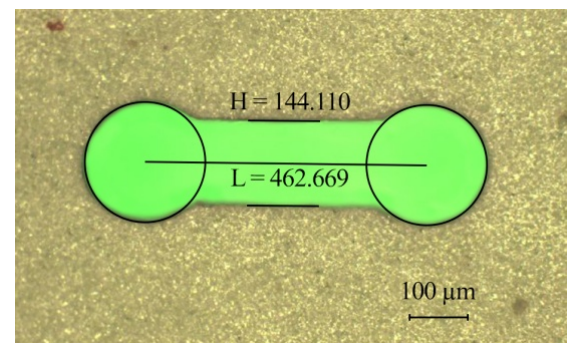

(a)

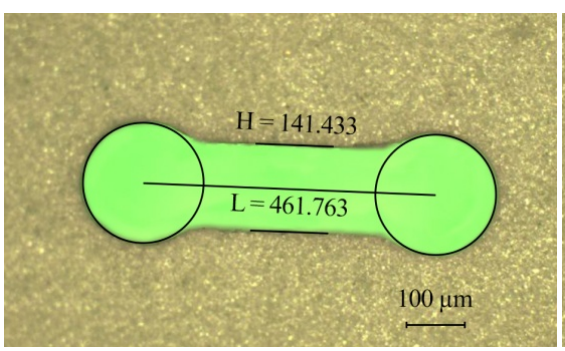

(b)

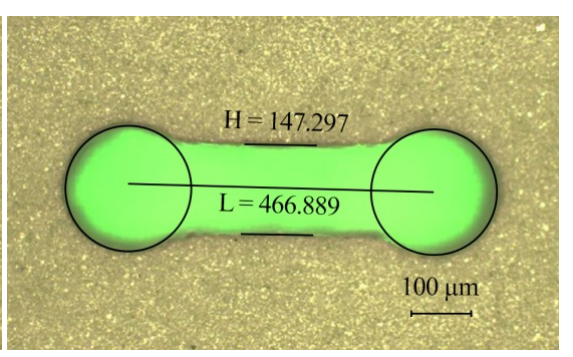

(c)

Figure 10. Measured dimension of (a) $250 \mu \mathrm{m}$, (b) $300 \mu \mathrm{m}$ and (c) $600 \mu \mathrm{m}$ pre-sintered holes on its top view. 


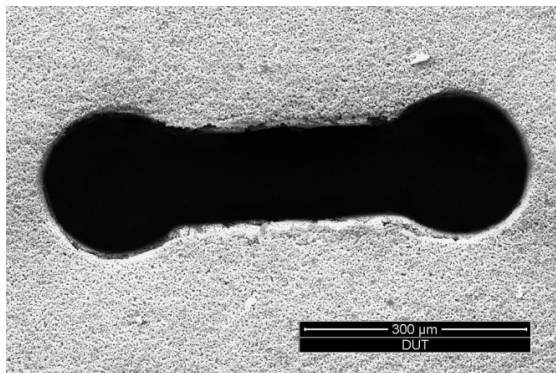

(a)

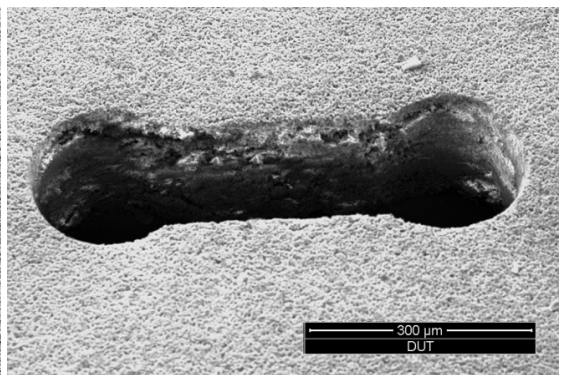

(b)

Figure 11. (a) Top and (b) tilted SEM view of $300 \mu \mathrm{m}$ sheet punched at $120 \%$ of thickness and $20 \mathrm{~mm} / \mathrm{s}$.

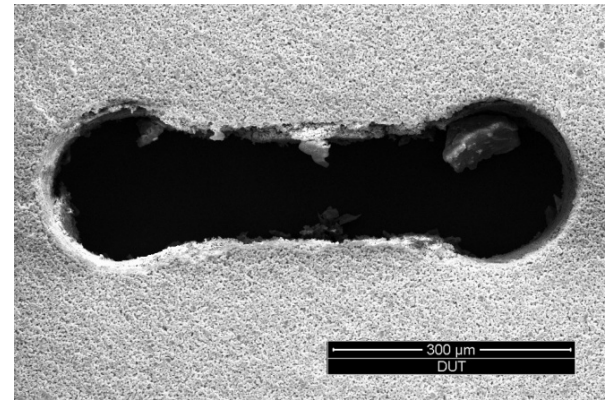

Figure 12. SEM image of a $600 \mu \mathrm{m}$ LTCC sheet punched at $20 \mathrm{~mm} / \mathrm{s}$ and $120 \%$ of thickness punch depth.

\subsection{Variable Gap Experiment Results}

Three sets of samples were taken for each gap clearance tests. Male punch tool with no offset would have a gap of $10 \pm 2 \mu \mathrm{m}, 5 \mu \mathrm{m}$ offset to have a gap of $5 \pm 2$ $\mu \mathrm{m}$, and $10 \mu \mathrm{m}$ offset to be $0 \pm 2 \mu \mathrm{m}$. Results of the experiments can be seen in Table 4. Results were calculated based on an average of 5 measurements on the same sample. Agreeing to earlier experiments that hole sizes correspond more towards female die size, we take the female die size as the target height and length. The outcome unexpectedly shows that the different gaps do not have a major impact on the overall hole size.

Displacement averages at $2.700 \mu \mathrm{m}$ across the different offsets, showing promising results. Figure 13 compares the three different gaps corner and surface smoothness: It is noticeable that the two smaller gaps does have an impact on the quality of the corners. The largest gap creates a rather slanted corner whereas the smaller has a sharper edge. That being said, these are small enough to be negligible. It can be assumed that the initial gap created by the tip with no offset, which resulted in a gap distance purely of the EDM feed, was already an adequate gap for LTCC process usage, and a smaller gap would only reinforce it.

\subsection{Post-Sintering}

SEM image on Figure 14 shows a post co-fired complex hole. This substrate was punched at $10 \mathrm{~mm} / \mathrm{s}$ at $110 \%$ of its thickness. No apparent burrs are seen on any of the corners and surfaces of the holes as is typical in sintered LTCC. Sintered 
substrates also had good mechanical character and the complex shape was not deformed in any way. The fragile stages of the substrate when all its binders and plasticizers evaporate and where it loses a portion of its volume did not destruct the complex shape from its initial profile. Similarly, the densification of the tape looks to be uniform and does not injure the original shape.

On average, the holes shrink on its length slightly more than on its height. Table 5 shows that taken the average, L shrinks $13.18 \%$ and $\mathrm{H}$ shrinks $10.41 \%$. This does cause a slight misshape of the two circles and rectangle, but would also be apparent on normal post-sintered circular via holes at a similar rate.

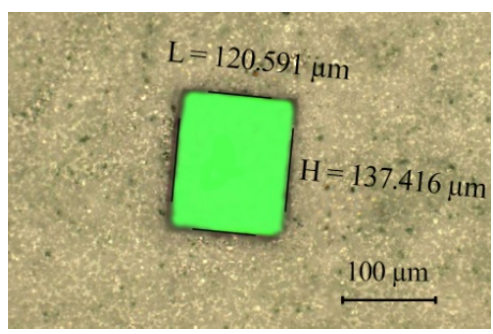

(a)

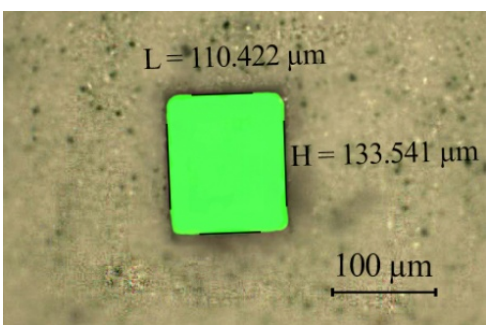

(b)

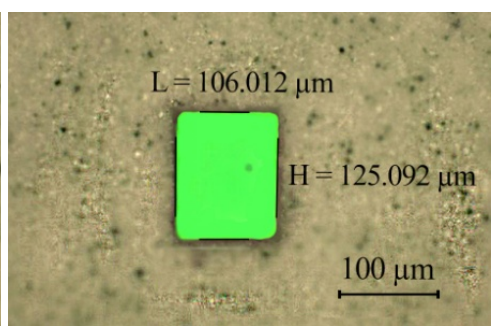

(c)

Figure 13. Microscope measurements of rectangular via hole on a $300 \mu \mathrm{m}$ LTCC sheet with different punching clearance of (a) $10 \mu \mathrm{m}$, (b) $5 \mu \mathrm{m}$ and (c) $<2 \mu \mathrm{m}$ respectively.

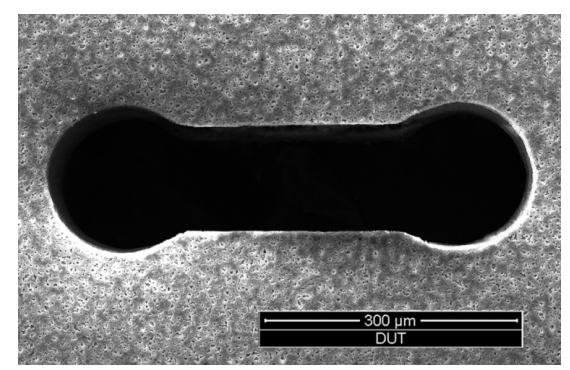

Figure 14. Entrance side of sintered complex via hole on a single layer $300 \mu \mathrm{m}$ LTCC sheet.

Table 4. Variable gap punch on a $300 \mu \mathrm{m}$ LTCC sheet measurement result (in $\mu \mathrm{m}$ ).

\begin{tabular}{ccccccc}
\hline & \multicolumn{2}{c}{ No offset } & \multicolumn{2}{c}{$5 \boldsymbol{\mu m}$ offset } & \multicolumn{2}{c}{$10 \mu \mathrm{m}$ offset } \\
\cline { 2 - 7 } & H & L & H & L & H & L \\
\hline Sample 1 & 137.416 & 120.591 & 133.541 & 110.422 & 125.092 & 106.012 \\
Sample 2 & 139.249 & 125.122 & 133.174 & 112.794 & 124.235 & 101.146 \\
Sample 3 & 140.345 & 122.492 & 134.962 & 112.145 & 124.646 & 105.228 \\
\hline
\end{tabular}


Table 5. Sintered LTCC complex hole dimension measurement and shrinkage rate.

\begin{tabular}{|c|c|c|c|c|c|c|c|}
\hline \multirow{3}{*}{ Speed } & \multirow{3}{*}{ Depth } & \multicolumn{6}{|c|}{ Sheet Thickness } \\
\hline & & \multicolumn{2}{|c|}{$250 \mu \mathrm{m}$} & \multicolumn{2}{|c|}{$300 \mu \mathrm{m}$} & \multicolumn{2}{|c|}{ Ave. Shrinkage } \\
\hline & & $\mathbf{L}$ & $\mathrm{H}$ & L & $\mathrm{H}$ & L & $\mathrm{H}$ \\
\hline \multirow{3}{*}{$\begin{array}{c}1 \\
\mathrm{~mm} / \mathrm{s}\end{array}$} & $100 \%$ & 405.197 & 132.577 & 405.398 & 130.166 & $12.99 \%$ & $9.91 \%$ \\
\hline & $110 \%$ & 401.897 & 128.293 & 402.889 & 129.339 & $13.27 \%$ & $10.31 \%$ \\
\hline & $120 \%$ & 402.233 & 124.671 & 401.166 & 125.308 & $13.10 \%$ & $11.02 \%$ \\
\hline \multirow{3}{*}{$\begin{array}{c}10 \\
\mathrm{~mm} / \mathrm{s}\end{array}$} & $100 \%$ & 397.688 & 130.165 & 403.988 & 128.089 & $13.16 \%$ & $10.12 \%$ \\
\hline & $110 \%$ & 401.908 & 128.345 & 399.925 & 126.673 & $13.26 \%$ & $10.69 \%$ \\
\hline & $120 \%$ & 398.811 & 126.734 & 400.171 & 125.996 & $13.22 \%$ & $10.25 \%$ \\
\hline \multirow{3}{*}{$\begin{array}{c}20 \\
\mathrm{~mm} / \mathrm{s}\end{array}$} & $100 \%$ & 401.429 & 130.127 & 400.559 & 124.929 & $13.15 \%$ & $10.19 \%$ \\
\hline & $110 \%$ & 400.931 & 125.312 & 399.249 & 127.194 & $13.25 \%$ & $10.76 \%$ \\
\hline & $120 \%$ & 400.702 & 125.174 & 399.266 & 126.015 & $13.16 \%$ & $10.47 \%$ \\
\hline
\end{tabular}

\section{Conclusion}

In this paper a more complex shape is chosen as a substitute for a circular shape via hole in the LTCC processing. Punching experiments done with different parameters bore different outcomes. It can be concluded that punching speed is less of a factor than the travel distance of the punch as seen in Graph [1]. Promising results are found on complex shape holes on sheets with a thickness of 250 $\mu \mathrm{m}$ and $300 \mu \mathrm{m}$ at both pre and post sintering stages. The thicker $600 \mu \mathrm{m}$ sheet however exhibited poorer result with larger offset and drafted surfaces. The good condition of these sheets post-sintering gives a strong argument in the actual usage of more complex shape via holes. Different gap sizes conducted on rectangular shape demonstrate that a gap of $10 \mu \mathrm{m}$ is sufficient for punching LTCC sheets as is commonly used in the industry. Any value below the offset of $10 \mu \mathrm{m}$ does not give a significant improvement in the measured size, albeit fabricating a slightly sharper edge.

\section{Conflicts of Interest}

The authors declare no conflicts of interest regarding the publication of this paper.

\section{References}

[1] Dominik, J., Thomas, M., Arkadiusz, D., Marina, S.K., Darko, B., Heike, B. and Jens, M. (2015) Overview on Low Temperature Co-Fired Ceramic Sensors. Sensors and Actuators A: Physical, 233, 125-146. https://doi.org/10.1016/j.sna.2015.05.023

[2] Baker, A., Lanagan, M., Randall, C., Semouchkina, E., Semouchkin, G., Rajab, K.Z. and Eitel, R. (2005) Integration Concepts for the Fabrication of LTCC Structures. International Journal of Applied Ceramic Technology, 2, 514-520. https://doi.org/10.1111/j.1744-7402.2005.02052.x

[3] Kumar, S. and Vadiraj, A.M. (2016) Smart Packaging of Electronics and Integrated 
MEMS Device Using LTCC. International Conference on Active/Smart Materials (ICASM-2009). eprint arXiv:1605.01789.

[4] Birol, H., Maeder, T., Jacq, C. and Ryser, P. (2005) Investigation of Interactions between Co-Fired LTCC Components. Journal of the European Ceramic Society, 25, 2065-2069. https://doi.org/10.1016/j.jeurceramsoc.2005.03.182

[5] Rosidah, A. (2012) The Effects of Sintering Temperature Variations on Microstructure Changes of LTCC Substrate. Sintering of Ceramics-New Emerging Techniques, No. 1, 60-84.

[6] Michael, G., Gregg, B., Cristie, L., Brent, D. and Larry, Z. (2009) Response Predicting LTCC Firing Shrinkage: A Response Surface Analysis Study. Journal of Microelectronics and Electronic Packaging, 6, 114-118.

https://doi.org/10.4071/1551-4897-6.2.114

[7] Gunter, H. and Lars, R. (2006) Fabrication of Smallest Vias in LTCC Tape. 1 st Electronic System Integration Technology Conference, Dresden, 5-7 September 2006, 642-647.

[8] Yu, Z.Y., Li, D.P. and Yang, J.F. (2019) Fabrication of Micro Punching Mold for Micro Complex Shape Part by Micro EDM. The International Journal of Advanced Manufacturing Technology, 100, 743-749. https://doi.org/10.1007/s00170-018-2731-1

[9] Fujino, M., Yamamoto, M. and Masuzawa, T. (1987) Micro-Punching System as an Application of WEDG. Institute of Industrial Science, 39, 277-280. (In Japanese)

[10] Chern, G.L., Wu, Y. and Liu, S.F. (2006) Development of a Micropunching Machine and Study on the Influence of Vibration Machining in Micro-EDM. Journal of Materials Processing Technology, 180, 102-109. https://doi.org/10.1016/j.jmatprotec.2006.05.010

[11] Rhim, S.H., Shin, S.Y., Joo, B.Y. and Oh, S.I. (2006) Burr Formation during Micro Via-Hole Punching Process of Ceramic and PET Double Layer Sheet. International Journal of Advanced Manufacturing Technology, 30, 227-232. https://doi.org/10.1007/s00170-005-0058-1

[12] Joo, B.Y., Rhim, S.H. and Oh, S.I. (2005) Micro-Hole Fabrication by Mechanical Punching Process. Journal of Materials Processing Technology, 170, 593-601. https://doi.org/10.1016/j.jmatprotec.2005.06.038

[13] Monika, D., Suri, N. and Khanna, P.K. (2013) Optimization of Shrinkage and Surface Roughness of LTCC Tape. International Journal of Research in Engineering and Technology, 2, 441-444. https://doi.org/10.15623/ijret.2013.0209067 